\title{
USE OF AN INTERDISCIPLINARY SUSTAINED Mentoring Collaboration to Enhance Teaching and to Develop A Tool Kit for Continued Growth
}

Christopher P. Aquino, Paul f. Vermette, and Taylor Roe

Christopher P. Aquino is Assistant Professor of Accounting, Paul J. Vermette is Professor of Education, and Taylor Roe is double major account and education student at Niagara University.

\begin{abstract}
During the 2012 spring semester, three individuals who care deeply about the quality of teaching and learning in higher education embarked on a journey with the humble goal of improving the teaching ability of a single accounting professor. This goal was broadened when they realized the "model" they developed had general application. The model included sustained mentoring across an entire semester followed closely by communications among the team members. The uniqueness of their approach included the addition of a student who was double-majoring in education and accounting to the team.

It should be noted that this study is an extension of a similar study recently completed by two of the authors. The previous
\end{abstract}


study produced the "Driver/Guide" model. This study extended the model to include the perspective of a student and the creation of a detailed list of teaching tools developed and implemented in the class. Though the studies were similar in nature, the results achieved in this study confirmed the robustness of the Driver/ Guide model and further validated its usefulness and applicability. As such, there are numerous references to the Driver/Guide 2011 study in this paper.

Keywords: interdisciplinary, sustained mentoring, collaboration, teaching and learning, student researcher

\section{INTRODUCTION}

During the spring semester of 2012, three individuals who care deeply about the quality of teaching and learning in higher education embarked on a journey with the primary goal of enhancing the teaching skills of a single accounting professor at a small private liberal arts college in Western New York. This humble goal was broadened when they realized the "model" they developed may be replicable meaning others might benefit from its use as well. This is especially true for newly hired faculty who are more open to recommendations and often seeking ways to boost their impact in the classroom. Following the advice of peers at conference presentations of the Driver/Guide 2011 study, the authors decided to include a menu of tools employed as well.

The players in the study include an accounting professor ("Driver"), a veteran secondary education professor ("Guide"), and a graduating senior with a double-major in education and accounting who had previously taken classes with both professors ("Bridge"). Each brought a different set of skills, experiences, and perspectives to the study that were equally important to its success.

The target of the study was a freshman level management accounting class taught by the Driver. The course is the second in a series of freshmen accounting classes taken by all business majors (accounting 
and non-accounting) at the school. Most students in the class were freshmen and sophomores and less than half were accounting majors. An online business simulation program ("Glo-Bus") was used for the group project in the class (Ho and Aquino 2011) so the class already involved some active learning components.

The Driver and Guide ran a similar study in the Driver's 2011 freshman level management accounting class and were able to achieve positive results (Aquino and Vermette 2013.) Prior to working with the Guide, the Driver's teaching style involved mostly "one-way" lectures with PowerPoint used as "notes" for the Driver and documentation of the lectures for his students. The change inspired by the Guide was to a style with a greater emphasis on engagement, active learning and constructivism. The primary goal of the Driver/Guide 2011 study was to improve the teaching skills of the Driver. The chronicling of their experience led to the publication of the parameters of their sustained mentoring model. That study will be referred to herein as "Driver/Guide 2011 study." For the sake of differentiation, the 2012 study, which represented an extension of the Driver/Guide 2011 study, will be referred to as the "Driver/ Guide/Bridge 2012 study."

The purpose of the Driver/Guide/Bridge 2012 study was threefold. First, it was hoped the accounting professor's in-class teaching results would continue to improve by continuing the sustained mentoring that began in the Driver/Guide 2011 study. Second, it was hoped inclusion of a student on the team would provide a more "hands-on" perspective and offer greater insight into the hearts and minds of students in the class. And third, this time the deliverables would include a detailed list of teaching tools employed. This change came from recommendations of peers who had reviewed the Driver/Guide 2011 research at conference presentations.

\section{Driver/Guide 2011 Study}


Inspiration for the 2012 study came from the Driver/Guide 2011 study (Aquino and Vermette 2013.) That study involved the same Driver and Guide and the same freshman level management accounting course. Inspiration to add the Bridge to the team came from discussions between the Driver and Guide regarding means of further engaging the Driver's students. The Bridge role turned out to be extremely important to the study because it gave the Driver and Guide immediate feedback on what to change and whether the changes were working. In the opinion of the authors, the addition of the Bridge made the Driver/Guide/Bridge 2012 model a more effective tool in developing the teaching skills of the Driver than the Driver/Guide 2011 model. The web appendix outlines some of the similarities and differences of the two studies.

The Driver/Guide 2011 study was a success in a number of ways. First, the Driver's in-class teaching activities improved and the student's perception of the effectiveness of those activities (as reported in student evaluations) also improved. In addition, student performance year-overyear (versus 2010 classes) appeared to improve. However, it should be noted that no statistical evidence supporting this claim was gathered during the study.

The primary focus on the Driver/Guide of 2011 study was the interdisciplinary collaboration between the Driver and Guide in the use of a sustained mentoring model. However, a loud-and-clear message from the academic community was that the paper produced included little on exactly what was done in the classroom to achieve the results. Therefore, one additional goal of the Driver/Guide/Bridge 2012 study was to provide more detailed information on what was done in the classroom to assist those hoping to implement the Driver/Guide model.

An interesting sidebar to Driver/Guide 2011 study was that the two authors have become good friends and have collaborated on a number of other Scholarship of Teaching and Learning (SoTL) projects (Boyer 1987.) In addition, in each case where the Driver's classroom was involved, the Driver has "driven" the decisions and the Guide has merely 
observed and advised. In other words, the roles established for the 2011 study are still in play today and the sustained mentoring experience has continued.

In addition, the Driver, Guide and Bridge are also friends. One should not infer that friendship is a prerequisite or an even expected outcome of studies such as this, but it is certainly possible. The results of both studies were of mutual benefit to all parties. The Driver improved his teaching, the students in the target classrooms received a more effective in-class experience, the Guide extended his life's work to higher education and contributed to the next generation of teaching and learning at his school, and the Bridge received "hands-on" experience working with students and faculty in both of the disciplines. By the conclusion of the Driver/ Guide/Bridge 2012 study everyone had something to feel good about. As such, it is not surprising meaningful and lasting friendships blossomed from this work.

\section{The TeAM}

To better understand the study, it is necessary to know a bit about the team and what motivated each member to participate. The individual skills, perspectives, and experiences were equally important to the success of the study and each grew personally and professionally through participation in the study.

\section{DRIVER}

After more than 20 years in the corporate world, the Driver decided a career change was necessary. After his first adjunct teaching assignment at a community college, he was hooked. He realized he likely had been teaching his entire career, but this time it was on a much larger scale. In addition, the "mentees" he worked with in the corporate world were older and more easily motivated. Would the tricks he used to moti- 
vate employees (e.g., setting a high bar, working side-by-side with his charges, emphasizing accountability, and the extensive use of intrinsic and extrinsic rewards) transfer to the world of higher education? In a sense they did, but only for the best of students. So what about the rest of the class? Those who were there because their parents made them go to college or who were taking accounting because it was required for their major (e.g., marketing, economics, finance, etc.), or worse yet, those who cruised through high school never really being challenged by their teachers. This made teaching college students much more difficult than mentoring employees.

The Driver realized he knew almost nothing about how to engage and motivate young people. The lack of "feedback" he received from a good number of the students in his first few classes was evidence of this fact. This is when he decided to turn to the experts in the Education Department and where the Driver and Guide first crossed paths. The Guide taught a secondary education class at the school where the Driver was teaching. The Driver signed up for the class during his first semester at the school. The Guide emphasized research supported constructivist and active learning techniques in the class. The Driver absorbed as much as possible. Motivation was easy because the information was almost directly applicable to his work.

The process of implementing his newly acquired teaching skills was slow. Generally, his students responded well but some were still not engaged. The single education class had helped, but his teaching was not improving quickly enough. With the busy schedule of a newly hired tenure-track faculty (e.g., teaching, service, and research) additional education classes were not possible. When discussing the situation with the Guide, the Guide suggested they do research together instead. They agreed and decided the primary goal of their work would be to help the Driver become a more effective teacher. In addition, if they came up with anything useful they would share it with the academic community so 
others could benefit as well. Their initial work resulted in the Driver/ Guide model (Aquino and Vermette 2013.)

\section{GUIDE}

The Guide began working in higher education in 1985 and has since concentrated his studies, practice, and scholarship on the process of instructional improvement. He has published four books and more than 90 articles and led numerous presentations focused on this topic and the paradigm change toward active and integrated learning (Svinicki 2004.) The Driver's eagerness to become a more effective teacher paired well with the Guide's commitment to change and the tenor of the institution where they worked toward a pro-SoTL ethos (Boyer 1987.) The Driver appreciated the Guide's view of learning and human cognitive engagement (Bransford et al 2000) as an area of disciplined and structured research and one not simply of "style" or "philosophy" of teaching. The Driver's initial perception of the discipline of teaching was that it was somewhat non-rigorous and without theory. Through his work with the Guide, the Driver was delighted to find he was wrong.

\section{BRIDGE}

The new addition to the 2012 team was an ambitious student in her senior year that, at the time of the study, was pursuing degrees in both secondary business education and accounting. Her formal training in the disciplines of education and accounting gave her a unique and valuable perspective on the study. Adding to this value was the fact she had previously taken courses with both the Driver and Guide. In this study, this role is referred to as the "Bridge."

The Bridge's drive and past success as a student in the Driver and Guide's classes was one reason she was asked to join the team. Her love of both disciplines (accounting and education) was another. 


\section{BRC Journal of Advances in Education Vol. 2, No. 1}

Her "connectedness" with the minds of college students was a third. Combined, they fueled a new passion for the Bridge...research. The Driver and Guide were fortunate to have found someone with this unique skillset to join the team. As it turns out, inclusion of the Bridge on the team benefited the study and the Bridge herself (an active learning experience.)

Experiences outside of her coursework, especially working 20-30 hours per semester in local high school business classes as a part of her education degree requirements, gave the Bridge tremendous insight into what makes college-aged students "tick." Her primary role in the study was as a "voice" for the students in the class. The Bridge acted as an intermediary between the Driver and his students. Students were encouraged to approach the Bridge with questions and concerns about topics they may have felt uncomfortable discussing directly with the Driver. Having recently been a student in the same management accounting class and currently a student in the school, the Bridge was very approachable to the students in the class.

The Bridge helped the Driver and Guide see what was and was not working in the classroom under study. She provided the kind of feedback often missing in today's classrooms where students work hard at times to NOT stand out. Her unique perspective is rarely available in higher education research and it certainly added greatly to the study. In addition, the role of "critical analyzer" for the Driver and Guide allowed the Bridge to grow both personally and professionally as a student and future educator/accountant.

\section{STUDY}

The Driver/Guide/Bridge 2012 study was similar in nature to the Driver/ Guide 2011 study, but with three important differences. First, a senior who was double majoring in education and accounting at the time ("Bridge") was added to the team. This was done to infuse the "student" 
perspective into the research and to help the Bridge grow as an educator by seeing the classroom through the eyes of a teacher. Second, the set of specific teaching tools introduced into the class would be documented and reported. This was done per the advice of peers who had seen presentations of the Driver/Guide 2011 study. And third, a primary goal of the 2012 study would be the "continued" growth of the Driver's teaching skills. Once the "low hanging fruit" had been harvested (Driver/Guide 2011 study), would the model continue to be effective? This question would need to be answered.

As was the case with the Driver/Guide 2011 study, a primary goal of the 2012 study was the growth of all team members. The authors were seeking ways of helping to develop teachers, but hoping to grow personally and professionally as well. If they were able to accomplish this, their work would have value regardless of whether anyone read the paper they would produce or implemented the model they would create.

The Guide and Bridge observed roughly $25 \%$ of the Driver's 2012 managerial accounting classes during the semester in question, meaning the mentoring was "sustained." Following each observation, the Guide crafted 4-5 reflection type questions for the Driver to provoke thinking and reflection from the Driver before any in-person discussions took place. Some were generic, like "What didn't go as planned?" and others were specific to the events of the day, like "Why did you run those activities early in class....as opposed to later, near the end?" It is critical to note these questions were not intended as proxies for criticisms (e.g., "Why in heaven's name would you think THAT was a good idea?") or hidden praise (e.g., "You do know that waiting awhile for a student to answer is a good idea, right?"). The content of these questions and specifically when to ask them were driven to a large extent by the theories of Ken Bain (Bain 2004) and Paul Vermette (Vermette 2009.) Bain and Vermette both take a learning-centered approach to teaching and learning. In addition, both propose that learning is done best by doing and through assessment (self and external). 
The questions asked by the Guide to the Driver in the Driver/Guide/ Bridge 2012 study were drafted with the intent of helping the "selfdirected" Driver to come to these truths on his own. If students learn best by doing and realizing some of what they saw as truth is not, so too should a higher education instructor. In this situation, the Driver became the "student" and the same philosophies he was encouraged to implement by the Guide were being used on him to make the decision to continue to do so.

The Driver responded in writing as soon as possible, and then often (not always) the Driver and Guide (and often the Bridge) sat and discussed the Driver's answers to the questions. To avoid influencing thinking before deep processing had occurred, the writing took place before the talking (see Kahneman 2011 for evidence of the wisdom in this practice.) Most supervisor experiences do not follow this pattern. Generally, the observer writes up his or her comments as declarative statements (e.g., "I liked that you waited 4 seconds before calling on a student" or "It is a bad move to keep calling on the same student when she is clearly not paying attention") not as true interrogatory statements. The Guide's role required asking real/non-threatening questions that demanded thoughtful/reflective answers from the Driver. Quickly, the practice became habitual and expected and their conversations became deeper, involved more teaching and learning theory, and the trust that makes organizations run effectively developed.

Below is an example of an email exchange that occurred between the Guide and Driver early in the semester to provide a flavor for these very important post-observation interactions:

Guide: As usual, much to digest. One question did jump out immediately. Pink (Pink 2009) and Deci's (Deci 1995) work on autonomy suggests that for routine tasks, profit matters, but to get the absolute max of performance...intrinsic has to kick in (and take over)..........we talked about this in my methods class 
yesterday....and I can show you how I am trying to take advantage of it.

DRIVER: I agree. I am just not sure how to get a person who did NOT really choose to learn the material (the ACC111 and ACC112 classes are REQUIRED for all business majors) intrinsically motivated. In other words, some in the class need the "carrots and sticks" and some would do much better with "autonomy, mastery, and purpose." The difficult part is figuring out who is who and then designing a class to satisfy both. I'd love to hear of how things went in your methods class.

The Bridge was less systematic in her approach. She occasionally sent email questions to the Driver similar to those of the Guide (with the Guide cc'd on all correspondence), but often did two additional things the Guide could not as follows:

(l) She brought the Driver specific suggestions or information from her observations of the class that she thought he should know. For example, one time (on her own accord) she counted the number of students who did not do the assigned in-class practice problems and provided this number to the Driver after class. Another time, she interviewed three students after class (again on her own accord), and reported their comments and concerns to the Driver. In all cases she maintained the anonymity of the students. The Bridge was able to speak to the students in the class as a "peer." This provided the Driver with greater insight into the hearts and minds of his students as they were much less intimidated by the 22 year-old Bridge than they were by the $50+$ year-old Driver and the $60+$ year-old Guide.

(2) She often "role played" as a student in the course and reported her impressions, confusions, clarifications, and criticisms of the teaching she observed. This was very powerful for she had already mastered the material and was developing a "deeper understanding" (Budwig 2013) and could now concentrate and share on her meta-cognitive insights. Ultimately, this meant more relevant and timely feedback for the Driver 
which enhanced his ability to modify his teaching. A semester moves very quickly and it is often difficult for a teacher to adjust "on the fly" without a continuous flow of relevant and timely feedback. This alone made the Bridge's role significant to achieving the goals of the study.

Conversation was at the heart of the investigation, so face-to-face meetings were scheduled regularly (approximately 8 over the course of the 14-week semester) to discuss the observations and interpretations of all team members. The focus of these discussions was always on the desired changes in teaching to be created and implemented by the Driver. As was the case during the Driver/Guide 2011 study and in line with the norm in higher education, the instructor made all decisions related to classroom teaching procedures. Many of the "new" procedures created were the result of email exchanges and in-person conversations of the Driver, Guide and Bridge.

And finally, data from semester end student evaluations was gathered and used to assess the impact of the changes in instructional methods made in the class. This is covered in more detail in the Results section.

\section{Teaching Tools}

Below are some of the specific teaching tools used by the Driver during the study. Each includes a record of the tool's origin, primary goal and frequency of use. The goal of this discussion is to provide a flavor of how the model worked and how these tools evolved from it. The outcomes of any replicated use of the Driver/Guide/Bridge model will likely be very different. In this study, the Driver's teaching improved and the Guide and Bridge grew professionally and personally, but only because of the unique combination of decisions made and the specific goals and intentions of the Driver. The tools worksheet developed (see below) is a byproduct of their work. Any use of the model by others will generate tools representing the specific interactions, intentions, and decisions of the team assembled to use it. As such, it will likely bear little resemblance 
to the one generated in this study. The key is whether the instructor's teaching improves and not whether the team generates or employs the same teaching tools described here.

\section{Concept Check (used once early on in the semester)}

\section{Source: Guide and Bridge recommendation}

\section{Goal: feedback, empowerment, and community}

A list of freshman level financial accounting class (fall 2011) concepts that would show up in the freshman level managerial accounting class (spring 2012) were distributed to students near the end of the first class. Students were asked to identify concepts they knew stone cold, knew something about, or knew nothing at all about. The completed worksheets were collected and tallied by the instructor and the next few classes were tailored to accommodate the most widely misunderstood concepts.

\section{Blackboard (used throughout the semester)}

Source: Driver (recommended by school for use in all classes)

\section{Goal: structure and organization}

A class management software application was used as a "central depository" for all documents and links to online websites (e.g., syllabus, class schedule, practice exam questions, online homework manager link, business simulation group project diary link, exam grades, etc.) This is a common feature of most higher education classes, but it is mentioned here because it was implemented with the purpose of providing structure and organization for the course. Students were highly encouraged to use the website whenever they needed any information about the course and no paper documents were ever distributed by the instructor. Of course, this meant that the instructor needed to ensure that all important information was added to the site and in a timely manner.

\section{Q\&A Email (used extensively during the semester)}




\section{Source: Driver}

\section{Goal: safe environment, feedback, and community}

If a student sent a question whose answer may benefit others in the class, the student's question and instructor's answer was sent to everyone in the class. This helped solidify the classroom community and anonymously provided praise to the student who was "brave" enough to submit the question. Students generally felt pretty good about helping their classmates. This tool was created by the Driver for the sake of efficiency, but turned out to be a very popular learning aide for the students.

\section{4. "Full Pads" POP QUIZ (used only a few times during the semester)}

\section{Source: Driver}

\section{Goal: exam preparation}

This exercise was intended to get students out of their comfort zone for a moment in the hope they would be more comfortable on their own during exams. An unannounced "quiz" was initiated and students worked alone and in silence for a portion of the class. After an appropriate amount of "self" work time, the students were encouraged to quickly "work the room" to find the correct answers from their classmates. The primary goal of the exercise was to wean the students off of the group to better prepare them for exam conditions. The surprise element of the quiz seemed to help accomplish this goal as the students were not sure whether or not the score would count. Although used successfully by many instructors as a motivator for pre-class preparation by students, use of "pop quizzes" can be counter to the development of a safe learning environment and were therefore not considered for use by the Driver in our study.

\section{Howdy Partner Groups (used extensively during the semester)}




\section{Source: Driver, Guide and Bridge discussion}

\section{Goal: safe environment and collaboration}

This tool was used for in-class assignments with the goal of getting students to work with other members of the class. Students were asked to change up partners both mid-assignment and between assignments. They were encouraged to introduce themselves with "Howdy Partner" as they moved about the room in search of new teammates. Most often this technique was used for assignments requiring groups of only two students. As corny as it sounds, the students seemed to enjoy the routine and the mechanical nature of the introduction process helped "break the ice."

\section{Cobwebs (used a few times during the semester)}

\section{Source: Guide and Bridge recommendation}

\section{Goal: prior knowledge and deep thinking}

Students were given a handout exercise as an in-class assignment. First the students got familiar with the problem by reviewing and making notes without the benefit of lecture or group assistance. Next the "cob webs" were shaken off and targeted lecture by the instructor was added. The students were encouraged to take notes on the handout during the lecture. Because they had seen the problem before the lecture, they were searching for clues to solve the problem making the lecture "relevant." Of course, the instructor helped them see some of the clues while he lectured. Next, the students took another shot at the problem with the instructor's help (a roaming guide) and the help of their classmates. And finally, the solution was modelled by the instructor from start to finish. They were encouraged to take notes on the handout during the modelling process. The exercise involved effort, collaboration, note making, self-assessment and successful completion of the task. It took a bit of time to implement, but it was worth it because the students pieced the solution together and had notes on how they did it. 


\section{Ratio Treasure Hunt (used once before exam \#2)}

\section{Source: Driver, Guide and Bridge discussion}

Goal: note-making (Vermette 2009), exam preparation and attendance

After passing out two documents (a set of financial statements and a list of ratio formulas) and explaining that the same list of ratio formulas would be provided on exam \#2, the instructor lectured on $15+$ ratios with an emphasis on where on the financial statements data for the ratios was and an interpretation of each ratio's usefulness. With about 15 minutes left in class, the instructor asked the students to take seven minutes to calculate as many of the ratios as possible from the financial statement data provided. Their goal was 10 correct answers which would earn 10 extra points on Quiz 1 of their group project (due shortly). Quiz 1 was worth $10 \%$ of the group project grade which was worth $20 \%$ of the final grade in the class. In essence, this "surprise" extra credit assignment, assuming they got 10 correct answers, was worth $2 / 10$ of $1 \%$ of their final grade in the class. In the end, they had a document representing their own "note making" (along with the exact list of ratio formulas they would be provided on the next exam) to study from. In addition, only those students who attended class were eligible for this extra credit and the hope was that the word get out that coming to class might actually help you pass the class.

\section{Got It!/Don't Got It! (used a few times during the semester)}

\section{Source: Driver, Guide and Bridge discussion}

Goal: collaboration, note making (Vermette 2009) and exam preparation

The goal of this assignment was to pair students who understood difficult topics (e.g., time value of money) with those who did not and to have them teach each other. Students were asked to raise their hands to show which group they were in (Got it! or Don't Got it!) and those who 
understood the concept were matched up with those who did not. Once paired, each student took turns providing suggestions on the next step of a complex capital budgeting problem (handout). A blank timeline and short problem with multiple parts was provided and teams were asked whether the project should be accepted by the hypothetical company.

Upcoming exam \#2 would contain a similar problem so this in-class assignment was good preparation for the exam. The students were not told specifically what would be on the exam, only that this exercise was important. The worksheets were collected and participants were given credit for completing an in-class assignment. The worksheets were reviewed by the instructor and returned to the students at the beginning of the next class for use in exam preparation.

\section{Pre-exam Review Classes (used before all exams during the semester)}

\section{Source: Driver}

\section{Goal: exam preparation and feedback}

At least one optional review session was run for every regular exam (3) and two more were run for the final exam. Seating was limited (30-40, depending on available classrooms) and ALL freshmen managerial accounting students in the school (six classes) were invited. The Driver's students had "first shot" at a seat because the invitation to students in other classes was delayed by approximately two days. The review classes were always full and always full of energy. The sessions were informal, discussion based, driven by student questions and the students generally prepared well for them. As such, the instructor received excellent feedback on how the course was progressing from conversations during these sessions (much better than the regular classes). In addition, significant positive feedback was received from the post-class student evaluations. This feedback came through the comments section because the evaluation form was not designed to capture it directly. The fact students 
made the extra effort to "write in" comments about the review classes made the feedback even more informative and valuable.

10. Glo-Bus Diary (used extensively during the second half of the semester)

\section{Source: Driver, Guide and Bridge discussion}

\section{Goal: reflection, feedback and empowerment}

Students worked in teams of 3-4 managing the annual decisions of a hypothetical camera assembly company by way of a business simulation application called "Glo-Bus." The assignment began after week five (of 14) and continued until the end of the semester. This project represented $20 \%$ of the student's final grade in the class and was made up of numerous sub-assignments (both group and individual.) One of these "sub-assignments" was the maintenance of a diary (or Blackboard journal.) Students were asked to make at least one entry per week related to any aspect of the group project. The journal was a direct and exclusive communication with the instructor with the only requirement being the topic must be Glo-Bus related. The idea was to allow students to "vent" risk-free while providing the instructor with useful feedback about the project. To ensure the students that their voice was being heard, the Driver sent an email to the class summarizing what had been discussed in the journals the previous week (individual comments were never specifically addressed) and how he might change the project specifications (if necessary) based on those comments.

\section{Email communications (used extensively during the semester)}

\section{Source: Driver}

\section{Goal: feedback, empowerment and community}

In general, modern day students do not speak up much in class, but they will communicate if the instructor encourages electronic commu- 
nication. Unfortunately, this means the instructor must respond to their email in a timely manner. A long delay or lack of response will increase the risk of losing this valuable feedback source. Instructors should keep this in mind when they are tired, it is late and there are 25+ student email messages in their inbox. Even a short response such as "I need more time." or "Let's talk about this after class." will encourage students to continue sending feedback through email. In addition, because many other faculty members do not respond to student email in a timely manner or even at all, the instructor will likely receive favorable comments and high marks on his or her end-of-semester student evaluations. This practice was used by the Driver in our study because it was good business practice he successfully employed during his $20+$ years in industry. An added benefit was the Driver, by way of example, modelled good professional behavior to his business students.

A closer review of the items presented above indicates that numerous research-supported teaching tools were created and employed in the Driver's class. Some were inspired by the Guide and Bridge directly (Concept Check and Cobwebs), others were born from a combination of a Guide/Bridge recommendation and Driver modification (Howdy Partner Groups, Ratio Treasure Hunt, Got it!/Don't Got it!, and Glo-Bus Diary), and still others were created by the Driver on his own (Q\&A Email, "Full Pads” POP Quiz, Pre-exam Review Classes, etc.) Each was purposeful and had particular goals in mind. Specifically important to the Driver in this management accounting class was the creation of a safe environment, solicitation of meaningful feedback, collaboration among students, empowerment and exam preparation. These issues were important to him personally and/or to achieving success in a relatively heavy content and technical class such as management accounting. An understanding of the "personal" set of desired outcomes for the Driver's classroom allowed the Guide and Bridge to help him build and integrate the necessary teaching tools to achieve his goals. In essence, the plan was customized to achieve the specific goals of the Driver. 
Other desired outcomes in this study included the establishment of structure and organization in the classroom, establishment and application of prior knowledge, deep thinking, note-making (Vermette 2009), reflection, and community building. Each is widely supported in teaching and learning research. The frequency of use and when they were introduced in the course was another important factor in each tool's effectiveness. For example, Concept Check was used in the first class as a means of uncovering the students' understanding of key concepts from their freshman financial accounting class taken the previous semester. The "key concepts" were financial accounting concepts that were important for success in the management accounting class (e.g., debits, credits, t-accounts, inventory cost-flow assumptions, financial statements, gross profit, etc.) The results of the very quick endof-class "survey" were used to plan upcoming classes with the goal of improving student understanding of key concepts identified as "low." The students were told of the purpose of the survey when it was administered and again when the key concepts they ranked as "low" were introduced in more detail in future classes. This was done to increase empowerment and to show their opinions mattered. It also helped build community because their responses affected the direction of the class for all students. All of this was intentional and preplanned by the research team.

A point worth emphasizing is that a number of the tools employed in the class were "created" by the Driver either on his own accord or from suggestions presented to him by the Guide and Bridge during the Driver/Guide/Bridge 2012 study and/or the Driver/Guide 2011 study. An example was a tool referred to as "Q\&A Email." After learning of the benefits of a safe learning environment, student feedback and community building in the Guide's Secondary Education class, the Driver worked hard to integrate these principles into his classes. Q\&A Email was born when the Driver found he was answering the same questions over and over again via email and decided instead to share responses to certain critical questions with the entire class. The Driver always 
made sure to thank the student who sent in the question (without ever acknowledging exactly who they were) and to encourage further questions. Students had a voice and felt their contributions helped the entire class. This simple teaching tool turned out to be one of the most significant and powerful outcomes of the study and is still in use in all of the Driver's classes today.

In a sense, the Driver not only improved his teaching effectiveness, but also learned to "adapt" and create new teaching tools on his own. Some of the tools outlined above demonstrate an "evolution" on the part of the Driver as both an educator and innovator of new teaching techniques. This was a very exciting and unexpected outcome of the study.

Much of the contribution provided by the Guide and Bridge related to the area of student collaboration (e.g., Howdy Partner Groups, Got it!/ Do't Got It!) The Driver had been in many accounting classes in his life as a student, instructor, and observer and had never seen this practice used. The classroom became a "workshop" as students worked together to solve problems. These tools were very effective and the energy level of the class rose every time they were used. In addition, because students were asked to pair with "strangers" every so often, they began to feel more comfortable in the classroom and the Driver's goal of a safe environment was furthered. Given the Driver's life experiences, it is unlikely he would have ever used in-class collaboration as a teaching tool had it not been recommended by the Guide and Bridge in this study. This is an example of where the collaboration of accounting and education can truly make a difference in higher education classrooms.

Other popular tools used and their primary goals included pre-exam optional review classes (exam preparation and feedback), a required weekly diary entry related to the Glo-Bus group project in the class (reflection and feedback), and quick response to email (feedback, empowerment, and community). Blackboard was used as a central depository for all deliverables and information as a means of maintaining structure and organization. 
The Driver left the study with a "tool belt" of new teaching tools. In addition, he knew there was sound teaching and learning research supporting each of them. And finally, he now had first-hand evidence of their effectiveness. In the opinion of the authors', none of this would have been possible without the intervention of the Guide and Bridge.

\section{Results}

Student evaluations from the Driver's freshman level management accounting class for the past three years provided some interesting outcomes. The web appendix shows the results of three key questions posed in the student evaluations. In 2010, the Driver taught three (3) classes and received no direct intervention whatsoever from either the Guide or the Bridge (who was a student in one of the classes at that time.) These results can been seen in the "2010 (3) None" column in the table below. Admittedly, the Driver had already taken a Secondary Education Methods class from the Guide the previous semester (fall 2009), but he was in no way "expert" in the ways of teaching and learning and was not collaborating in a significant way with the Guide at that time.

In 2011, the Driver taught only one (1) freshman level management accounting class. This was the target of the Driver/Guide 2011 study and is referred in the table below in the "2011 (1) DG only" column. And finally, in 2012, the Driver again taught only one (1) freshman level management accounting class. This was the target of the Driver/Guide/ Bridge 2012 study and is referred in the table in the "2012 (1) DGB" column.

Though the studies were structured somewhat differently, a key result in observed in both was for question \#5 which measured student perceptions of whether "The instructor's in-class lectures/exercises helped me understand the material." This metric improved from 1.67 (of 5.0) to 1.56 (of 5.0) during the Driver/Guide/Bridge 2012 study after an improvement from 1.93 (of 5.0) to 1.67 (of 5.0) during the Driver/Guide 2011 study. 
Given the type of intervention involved in both studies (primarily the integration of new or modified "in-class" activities), this is the key empirical result of the studies.

Also impressive were results observed for question \#3, "This is an excellent teacher." Here the 2012 metric improved from 1.57 (of 5.0) to 1.20 (of 5.0) following an improvement of 1.80 (of 5.0) to 1.57 (of 5.0) the preceding year. In addition, question \#4, "I learned a lot in this class" improved from 1.77 (of 5.0) to 1.64 (of 5.0) during the 2012 study after improving from 1.91 (of 5.0) to 1.77 (of 5.0) in 2011. And finally, question \#1, "Considering all aspects of this course, I would rate the Total Quality of the course to be" saw an improvement from 1.73 (of 4.0) to 1.56 (of 4.0) in 2012 after an improvement from 2.19 (of 4.0) to 1.73 (of 4.0) in 2011.

One other result worth noting was for question \#10, "The instructor shows concern for his students" (not included in the table above.) Here the metric moved from 1.07 (of 5.0) in 2010 up to 1.37 (of 5.0) in 2011 and back down to 1.16 (of 5.0) in 2012. It is difficult to tell why the metric worsened in 2011 and then improved in 2012, but it is worth noting that all three results are excellent (where 1.0 represents "strongly agree".) To a large extent, this question measured whether the instructor successfully created a "safe learning environment" for his students. Of all the topics covered by the Guide in the secondary education class taken by the Driver, this is the one that most resonated for the Driver. As such, it was the area that received the greatest attention as he structured his first few classes. It was particularly rewarding for the Driver to learn that almost no development time was necessary to achieve excellent results in this area because it meant nearly every student who came through his classes felt safe. It is not a surprise that many of the teaching tools created under the Driver's direction during this collaboration had the development of a safe learning environment as a primary objective (see Teaching Tools above.)

In summary, the data taken from student evaluations between the years 2010-12 seem to indicate the classroom experience of students 
improved across both studies. Despite the fact the Driver was making all decisions, the recommendations provided by the Guide in 2011 and Guide and Bridge in 2012 seemed to have had a positive impact. In addition, because the Driver was "driving" at all times, the transformation was relatively painless and fit nicely with the autonomous and somewhat self-directed nature of higher education teaching improvement.

\section{Conclusions}

Listed below are observations from the Driver/Guide 2011 and Driver/ Guide/Bridge 2012 studies and the world of higher education in general.

- Collaboration between accounting and education faculty may be an effective means of overcoming the lack of teacher preparation in most $\mathrm{PhD}$ programs and most professionally qualified $(\mathrm{PQ})$ faculty member's paths to the classroom.

- The Driver/Guide model was used successfully twice; first during the Driver/Guide 2011 study (Aquino and Vermette 2013) and again during the Driver/Guide/Bridge 2012 study. This implies it may be replicable and useful to other faculty who hope to improve their teaching effectiveness.

- The earlier in a faculty member's career the "intervention" (or "collaboration") takes place the better because the number of students exposed to less than optimal teaching will be reduced. In addition, new faculty are often more open to change in their instructional methods than their more seasoned colleagues.

- High quality teaching may offer an opportunity for a school to distinguish itself from its competition. However, for this to happen good teaching must be supported and rewarded by the school's administration and promotion and tenure committee. It would also help if school ranking entities placed greater emphasis on good teaching and pedagogical research. Recommendation \#4 of the Pathways Commission Report, a joint initiative of the AICPA and AAA calls for "Reform in accounting education so that teaching is respected and rewarded as a critical component in achieving each 
institution's mission." (Pathway (2012), pg. 63). Further, it asks the academe to "Increase reward, recognition, and support for high quality teaching." (Objective 3.1, pg. 63), "Better connect faculty annual review, promotion, and tenure processes to the quality of teaching." (Objective 3.2, pg. 65), and "Improve how universities value the importance of teaching." (Objective 3.3, pg. 66). As such, our suggestion has significant support.

- Inclusion of a student in the research process may not only enhance the effectiveness of research, especially when the subjects of the study are students themselves, but it may also provide a wonderful learning experience for the student/researcher. As such, faculty should include students in their research whenever possible and special publication outlets should be made available to highlight this type of "hands-on" learning.

The web appendix also includes comments from the Bridge which demonstrate how she benefited from participation in the study.

\section{Applicability}

The authors believe the process of improving the in-class performance of a higher education faculty member as outlined in this paper is replicable. In addition, they feel it can be implemented in almost any higher education classroom (not just an accounting classroom.) And finally, that the earlier in the career of an educator it is implemented, the better it will be for everyone involved. The key is a full commitment from the participants and always letting the Driver "drive" the process. The autonomous, hands-off, tenure-centered world of higher education demands it.

The research team assembled for this study is certainly unique in regard to experience, skills and theirs close personal relationships. However, the model created is something that the authors feel can be replicated at any number of higher education institutions. One of the goals of the study was to provide details of the simple teaching tools built and employed to help other faculty see how easy it could be to 
use the model to improve their teaching. When someone is sick, they seek assistance from a medical expert. When they wish to learn to play tennis, they find a good tennis pro and take a few lessons. Therefore, if one wishes to become a better educator they should seek assistance of an education expert. This was done in this study and it changed the world of the Driver and his students in a positive way. The addition of the Bridge meant the impact was expanded far into the future because her entire career is in front of her.

Hopefully, learning of the results of this study and how the authors were able to achieve them may help improve your own teaching. Your students will benefit and you will be rewarded by knowing you have done all you can to help them become the best they can be.

\section{Limitations}

Admittedly, the study contains little empirical data and no verified performance assessment measures. In essence, it is a personal account of change and growth. However, the results achieved do indicate that student perceptions (per responses from end-of-course student evaluations) regarding the value of in-class activities improved. Some argue student evaluations positioned after the class has ended rarely allow for significant change (Knol, Van Driel and Mellenberg 2013.) However, a lifetime of research on student evaluations by Herbert Marsh (Marsh 2001) offers trust in students' comments but supplements them with other people's interventions (like the Guide and Bridge in this study) that are offered during the course, when thoughtful change can be made. This "during the course" intervention requires a commitment to the sustained mentoring approach (Bruns, Jackson, Janell, and Rupert 2004) we are investigating and assessing in this study and in the Driver/Guide study of 2011.

A second limitation is that all data came from a single classroom and there was no direct comparison group. The Driver taught only 
one freshman level management accounting class during the semester under study. However, it should be noted the study included frequent comparisons with the Driver/Guide 2011 study that occurred in the same freshman level management accounting class taught by the Driver. This year-over-year analysis, admittedly not a perfect comparison, did indicate improvement of teaching skills on the part of the Driver when he was exposed to the sustained mentoring afforded to him during the study. As such, the authors feel this limitation was somewhat remedied. Also, even if the Driver had been teaching more than one class in 2012, the authors feel it would not have been ethical to deprive the "control groups" of an anticipated improved learning environment simply for the sake of a more valid research result. This is a dilemma often faced by researchers seeking improvements in classroom teaching.

A third limitation relates to the applicability of the study to other classrooms. More specifically, to the issue of the uniqueness of the relationships shared by the Driver, Guide, and Bridge as close friends who thoroughly enjoyed working together; especially on this and other studies aimed at improving teaching at their institution. However, as a counter this charge it should be noted that to a large extent these "friendships" were born from or strengthened by working together and were not a pre-requisite of this work. In other words, the authors feel that "relative strangers" could successfully implement a similar program and that friendships may result as well. The shared expertise by committed educators toward a common goal of improved teaching is the only essential variable.

A fourth limitation regarding the applicability of the study relates to the tremendous support this initiative received from the authors' institution. Not only was good teaching expected and vigorously supported by their school, but scholarship of teaching and learning (SoTL) was recognized as valid and important research for tenure and promotion decisions. This means it was not necessary to risk their careers by engaging in this type of work as might be the case at other more "disci- 
plined-centered" research institutions. This was an important factor in the Driver and Guide's decision to engage in this (and the Driver/Guide 2011) study. Is institutional support necessary for successful implementation of such a program? The authors believe it is, but not to the degree they received at their institution.

\section{Closing Thoughts}

An interesting sidebar to this research is the impact "good teaching" has on teachers themselves. Mottet et al explains that (for the most part) teachers are intrinsically motivated. In other words, it is not the salaries they make or titles they carry that draw them to the profession, but it is instead the "quality relationships they develop and maintain with their students" that is paramount (Mottet et al 2004, pg. 154). These relationships are greatly enhanced by positive in-class verbal (e.g., asking and answering questions, participating in discussions, engagement in classroom activities, etc.) and nonverbal (e.g., nodding, sitting forward in one's seat, eye contact, etc.) responses from students. The quality of these responses further impacts the teacher's confidence in his or her ability to affect student learning (or "self-efficacy") and overall job satisfaction. In other words, improved classroom experiences for students can lead directly to a more highly motivated and happy teacher which can then lead to even better classroom experiences for students. This "multiplier effect" can be very powerful and further enhanced the value of this study.

Finally, the changes the Driver made in his teaching methods, his increased desire to develop them further, and the powerful preliminary results he found in his student learning outcomes flowed from the atmosphere of collaboration (across disciplines), Vincentian outreach (helping those less fortunate), constructivist teaching approaches (learning by active involvement and thinking) and supportive leadership that values teaching. All of these qualities are central to the success and mission of 
the school the authors were lucky enough to be a part of and they played a big role in the motivation for and success of this study.

\section{REFERENCES}

Aquino, C., and Vermette, P., (2013). Improving Teaching: A Sustained Mentoring Collaboration Between Accounting and Education. Advances in Accounting Education. 14, 101-130. http://dx.doi.org/10. 1108/S1085-4622(2013)0000014011

Bain, K. (2004). What the best college teachers do. Cambridge, MA: Harvard University Press.

Boyer, E. (1987). College: The undergraduate experience in America. Harper \& Row, NYC: NY.

Bransford, J., Brown, A., and Cocking, R. (2000). How People Learn: Brain, Mind, Experience, and School: Expanded Edition. Washington, D. C.: National Academy Press.

Bruns, S, Jackson, C, Janell, P., and Rupert (2004). An investigation of the use and perceived effectiveness of peer teaching observation for untenured accounting faculty. In J. Edward Ketz (Ed), Advances in accounting education teaching and curriculum innovations, 6, 173-192.

Budwig, N. (2013). The Learning Sciences and Liberal Education. Change: The Magazine of Higher Learning, 45(3), 40-48. http://dx.doi.org/10. 1080/00091383.2013.787271

Deci, E. (1996). Why We Do What We Do: Understanding Self-Motivation. Penguin Group (USA) Inc., NYC: NY.

Ho, S., and Aquino, C. (2011). "Glo-Bus Simulation in First Management Accounting Class: An Assessment," An integration of a 10 year journey, in Kot, P. ed., Case studies in active and integrated learning: Teaching innovations that make a difference. Cambria Press: Niagara University.

Kahneman, D. (2011). Thinking, Fast and Slow. New York: Farrar, Strauss, Giroux. 
64 BRC Journal of Advances in Education Vol. 2, No. 1

Knol, M., Van Driel, J. and Melleneberg (2013). Effects of feedback and consultation on University teachers' knowledge, attitudes, attention and skills in lecturing, presentation at American Educational Research Association annual conference, San Francisco: CA.

Marsh, H. (2001). Distinguishing between good (useful) evaluations and bad workloads on students' evaluation of teaching. American Educational Research Journal, 38 (1), 183-212. http://dx.doi.org/10.3 102/00028312038001183

Mottet, T. Beebe, S., Raffeld, P., and Medlock, A. (2004). The effects of student verbal and nonverbal responsiveness on teacher self-efficacy and job satisfaction. Communication Education, 53 (2), 150-163. http:// dx.doi.org/10.1080/03634520410001682410

Pathways Commission Report (2012). Jointly sponsored by American Accounting Association (AAA) and the American Institute of Certified Public Accountants (AICPA). July 31, 2012.

Pink, D. (2009). Drive: The Surprising Truth About What Motivates Us. Penguin Group (USA) Inc., NYC: NY.

Svinicki, M. (2004). Learning and Motivation in the Postsecondary Classroom. Josey-Bass, San Francisco: CA.

Vermette, P. (2009). ENGAGING teens in their own learning: 8 keys to success. Eye-on-

Education, Larchmont: NY.

\section{Web APpe ndix}

A web appendix for this paper is available at:

http://dx.doi.org/10.15239/j.brcadvje.2014.02.01.wa03

\section{Citation Information}

Aquino, Christopher P., Paul J. Vermette, and Taylor Roe. "Use of an Interdisciplinary Sustained Mentoring Collaboration to Enhance 
Teaching and to Develop a Tool Kit for Continued Growth.” BRC Fournal of Advances in Education 2, no. 1 (2014): 35-65. http://dx.doi.org/10.15239/ j.brcadvje.2014.02.01.ja03 